\title{
Scrutinizing Different Generations of Public Green Spaces in Iran in Terms of Sustainability
}

\author{
Elham Khademi, Mohamed Rashid Bin Embi, and Parastoo Khademi
}

\begin{abstract}
The first step in investigating or designing sustainable urban public green spaces is investigating on historic background and cultural values, environmental principles, economy sequences and aesthetics criteria of the society. Comparisons between different generation of public green spaces to revision and identify the symbolic concept of Iranian garden in terms of sustainability, is the main approach of this study. Common symbols in Iranian Gardens explained and the principles and aspects of sustainability in landscapes will be mentioned for better understanding of Persian gardens. Recently the loss of symbolic flourish and fundamental implications in architectural cerebration and contemplations as well as meaningless concepts cause open urban spaces demonetize to just cover the people's physical needs. With regard to the valuable concept of Iranian Paradise, inspiration of some western and foreign patterns without regarding their main concept seems to be vanquished in Iranian open spaces.
\end{abstract}

Index Terms-Green public space, iranian garden, iranian parks, sustainability.

\section{INTRODUCTION}

Sustainability has developed as a result of major concerns about the unintended social, environmental, and economic consequences of quick population growth, economic growing and consumption of natural resources. Three significant instructions each including different aspects of sustainability can be determined as below:

1) Preserving and improving environment to respect the environment.

2) Concerning today and future generations by cultural and society recognition.

3) Enhancing residents' quality of life.

Environmental sustainability is one of the most important sustainability factors in gardens to provide desirable micro climate by ecological consideration. Other item mentioned above is based on cultural and social aspects which formed Persian Paradises. For reaching sustainability, concerning societies and environment having the advantages for human life is essential. The improving of human life in sustain manner does not mean for currently problematic issues in a

Manuscript received January 20, 2013; revised September 2, 2013. The authors sincerely acknowledge Research Management Center (RMC), Universiti Technology Malaysia (UTM), and Ministry of Higher Education (MOHE) of Malaysia, for the funding of the research.

Elham Khademi is with the Universiti Technology Malaysia (e-mail: elham_eng1363@yahoo.com).

Mohamed Rashid Bin Embi is with the Department of Architecture, Universiti Technology Malaysia. (e-mail: b-rashid@utm.my)

Parastoo Khademi is with the Department of Civil Engineering, University of Shahrekord, Iran. (e-mail: p.khademi20@yahoo.com) way that does not cause further problems answers.

Omitting any life access but it means finding best Sustainability in the Persian Garden is involved with cultural and social backgrounds of this region. Respect and reverence for water and trees have been institutionalized in many ancient civilizations due to their various socio-cultural traditions, values and beliefs. The eastern people have always had a special attention toward green sites. Among them, Persian people have a very long history in the art of gardening and designing open-air spaces. In Iranian people's view, garden is a manifestation of paradise [1]. Thereby it is visualized full of flowers and trees and It is said that there are streams of drinking sweeter than honey and more useful than milk within, as well as water springs and high palaces. In the Holy Koran verses, paradise has been called with the names of Ferdos, Jannat, and Eram; Iranian gardens have been named with most of these names or some combinations of them.

Garden has always been the best space pattern to live as well as a desired and dream environment for the human beings residence. Perhaps, it is for the very reason and based on some of the religious sources that Adam and Eve, before getting departed to the earth, lived in the paradise which has been an immortal garden. In addition, based on the religious beliefs in divine religions, the pious and right doing humans will eventually enter the paradise garden in the resurrection. In studying or designing urban public green spaces, the first step is paying serious attention to cultural values, historic background, ideological principles, aesthetics criteria and environmental conditions of the society.

The architectural concept of the garden reflects the feeling of place or locality. It is because the garden is considered as an attractive space which frames inside the whole picture of the universe and make a qualified environment for residents and visitors. This concept which is the foundation of order and harmony can be sensed through number, geometry, color, and material. At the same time, it can turn the reason to the nature which is the inner aspect hidden in the positive atmosphere. Garden is a manifestation of the centrifugal face of the macrocosm [2]. Iranian garden is not only a safe and comfortable place, but also a place for calm thinking or philosophical negotiations, for deliberation and investigation, a place where the human's tired soul can be pepped up, relaxed, and opened to novel scenes. Chardin had noticed that Iranians are relaxed in their gardens and are not satisfied merely with breathing, but they smell greedily the odor of certain flowers [3]. There were legendary gardens in Isfahan, not only the famous Chahar-bagh (four gardens) which was in fact a park-like resort, but also numerous gardens which had surrounded it from all sides. 


\section{THE HISTORY OF GARDENING IN IRAN}

In Farsnameh, IbnBalkhi claims that Manoochehr, the son of Mishkhoriar, the seventh king of Pishdadi dynasty (Iranian dynasties pre - Islam are: Pishdadian, kianian, Ashkanian, and sassanid) was the first one who built the garden [4]. In the history of civilization (Belief period ), Will Durant writes : "Iranian style garden has been also imitated by the other countries, got common among the Muslims ,Arabs, and Indians, and has also inspired Europeans in the Middle Ages [5]. It has been found out through working on the writings of Greek historians that most of the Iranians' houses had been surrounded by the gardens about three thousand years ago, and so those gardens have been also called "paradise". The construction of Gardens been also imitated by other countries this Persian term has been sent to the farm lands. The very term is nowadays used exactly or with some changes in Greek, French, Sami, and the other languages across the world [6].

\section{MAIN FEATURES OF IRANIAN GARDENS}

A glance over the development and progress of Iran's architecture art show s that the architectures of this land, along with the simple purposes like solving dwelling problem and being safe against cold and heat, have also paid so much attention to such other issues as dividing the spaces based on different physical and mental requirements [7].

Most of gardens in Iran are square formed. Square is one of the complete and especially important and holy figures in the culture of architectural and urban designing in Iran. In the cases where the designs of eight paradises or four lines were used to design and build the palace complex and a porch was made in the middle of each of the four fronts of the complex which enjoyed the same conditions in terms of their physical and applicative standing and importance, a pond was built like the complex of Isfahan eight paradises in front of each one of the four porches. Across in Chahar-bagh design divides the square shaped setting of the garden into four sub-squares, and some streams can also divide each of these squares into four other smaller ones [8]. In addition, there is a pond at the junction point of this cross shaped figure as can be seen in Fig. 1 .

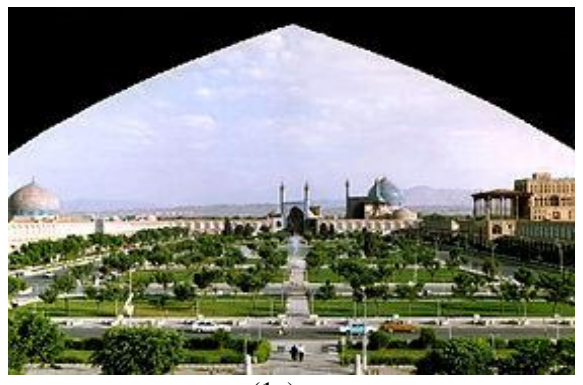

(1a)

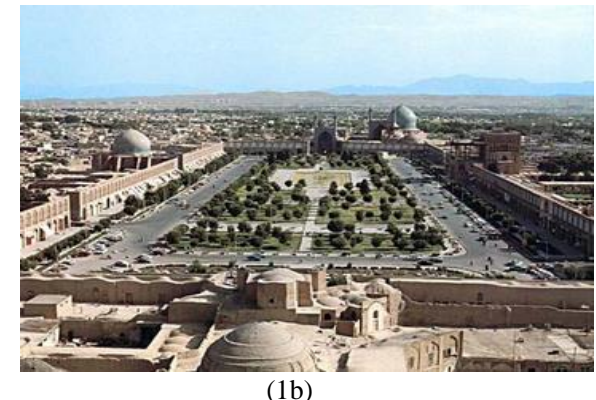

Fig. 1. The example of square division in Isfahan
1) Maps and plans were considered worthy of attention in ancient Iran, so square and rectangle shaper were highlighted (Fig. 2). We know that the Achaemenian kingdom gardens had exact rectangular designs with symmetric streets and trees [9].

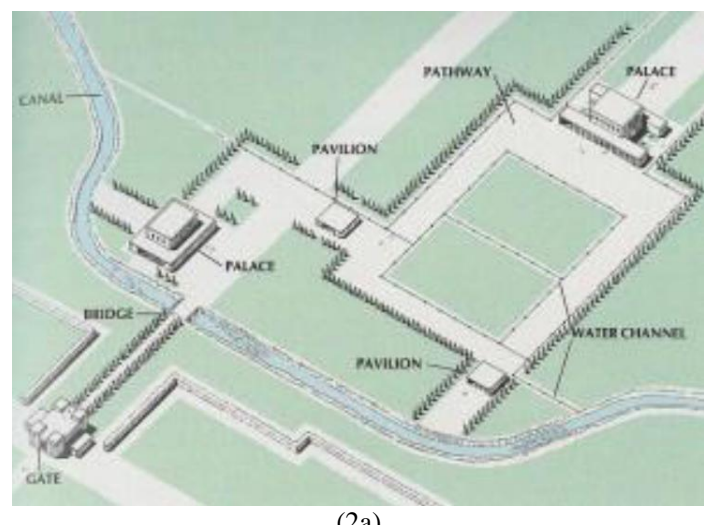

(2a)

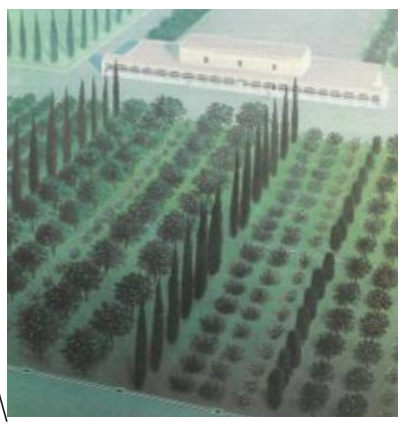

(2b)

Fig. 2. Achaemenian kingdom gardens

2) Number "four" and figuring square: As it has been found out, figures and geometrical numbers don't have just quantitative senses and faces, but they have also a qualitative and symbolic face which is not only real, but also like the quantitative face forms part of their realities. Number "four" is of the holy ones. It shows four cardinal points (North, south, East, and west), mankind's special body features (front, back, left, and right ), four basic existence elements (water, wind, soil , and fire), the year seasons (spring, summer, autumn, and winter), as well as the number of square sides and angles. Square is also one of certain geometrical figures, which has four equal sides and angles. These features bring forth by themselves many geometrical features as being inscribed on and in the circle, etc. Square is also a figure having symmetry, balance, and equilibrium.

3) Establishing the garden in a sloping land: Most of the Iranian gardens are made in sloping lands, in such a way that either a staircase is built in its middle for the water crossing through makes a pleasurable sound or if it is a little sloping as shown in Fig. 3., the irrigating system of Chahar-bagh is used in its making where water comes again from the upper level to the lower one. [9]. since most of Iran's land is situated in warm and dry areas and also there is a little rainfall, irrigating the trees is done by brooks and regular streams which this prevents water to be wasted. This shows that the best plan for making garden is the very quadrangle the Iranians have applied in all of their gardens. 


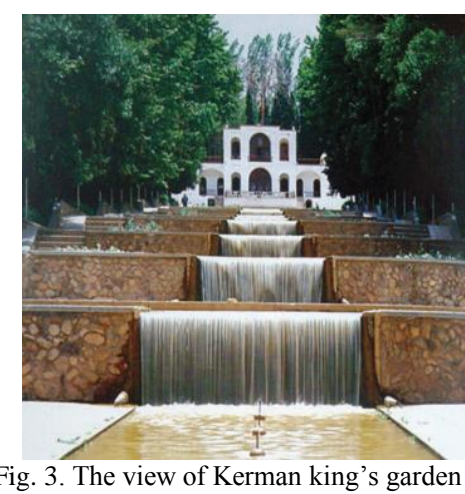

4) A close relationship between the nature of flower and tree planting: Fred Richards, English tourist, quoted in his diary the idea of Francis Bacon, the well-known philosopher and statesman of England's seventh century, about the gardens as follows: "Francis Bacon had fixed ideas about the garden which some of them indicate that he had travelled to Iran, while he had only travelled to Paris. About three hundred years ago, he wrote some things about gardening. In the garden, human being and nature were completely in the same route. It provided relaxations, convenience, and happiness." and the plants are placed in gardens in the way that they can adopt with their context and needs. [10].

- Existing a pond or pool to provide water and beauty of water-view and pool

- Dividing the garden area into almost always four parts

- Using the straight lines in designing the garden

- Existing a building at the center or the highest part of the garden space

- Using a main stream

- Having a close relationship with the nature and not existing any distances between the garden and building.

- Using many shady trees as well as narrow lanes.

\section{CONTEMPORARY URban GREEN SPACE}

After $19^{\text {th }}$ century, after industrial revolution Iran was influenced by a range of internal and external factors and passed through a new development process in urban and open space design. Entry of European modern architectural styles affected the appearance and meaning of the words of garden and park and Iranian gardening methods were impressed by European methods visually and conceptually. Although there are still traces of Persian garden in designing modern parks, but in most cases urban parks become places without any special identity that is unfamiliar for users (Fig. 4). With regard to the valuable concept of Iranian Paradise, inspiration of some western and foreign patterns without regarding their main concept seems to be vanquished in Iranian open spaces. Most of the open green spaces have been developed that need high amount of water for irrigation and it is not affordable for preserving in a dry country. Hence reviving and utilizing of these key elements of traditional green spaces play an important role to revitalize the spirit of the cities and enhance the sense of belonging among people.

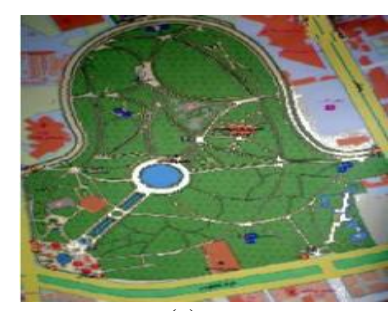

(a)

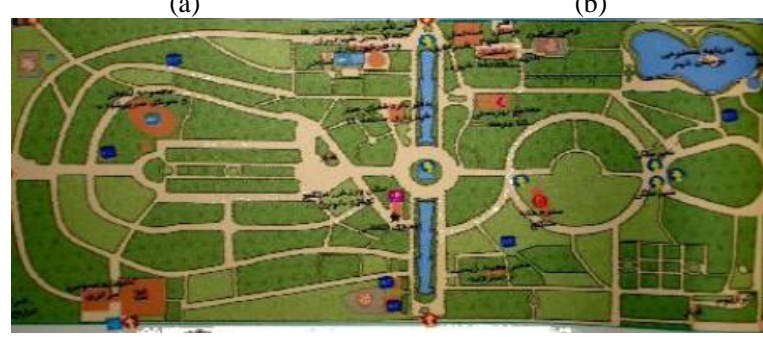

(c)

Fig. 4. (a) Laleh Park- Tehran, (b) Mellat Part- Tehran, (c) City ParkTeahran

\section{REFERENCES}

[1] M. Kiani, The History of Iran's Architecture Art in the Islamic Period, SAMT Publication, 1381, pp. 25-32.

[2] N. Ardalan and L. Bakhtiar, The Felling of Gnostic Tradition Unity in Iranian Architecture, Khak Publications, 1389, pp.12-25.

[3] A. Dehkhoda, Dehkhoda Dictionary, 1377.

[4] Ibn Balkhi and Fars-nameh, The Correction of Listrang and Nickson, London Press, 1921, pp.42-48.

[5] A. U. Pope, A Survey of Persian Art, 1388, pp.10-14.

[6] A. Arianpoor, A Research to Know Iran's Gardens and Historical Gardens of Shiraz, Golshan Publications, 1365

[7] H. Naier noori, Iran's Share in Global Civilization, Tehran Press, 1345.

[8] A. J Arbery, And Thirteen Orientalist, Iran's Heritage, Tehran Press, 1346.

[9] H. Sultanzadeh, "The continuation of Iranian garden designing in Tajmahal", The Office of Cultural Investigations, 1378, pp.17-23.

[10] J. Chardin, Journeys of Sir. Chardin, AUT Institute Press, 1335.

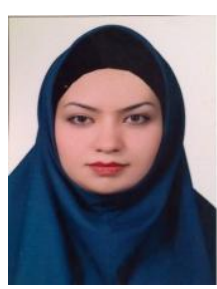

Elham Khademi was born in Shahrekord, Iran on September 16, 1984 and was graduated from University of Shahrekord, in mechanical engineering, Iran in 2007. In 2011 she received her master of science in urban design, from University Technology Malaysia. Now she is a Ph.D candidate of urban design in University Technology Malaysia.

She is a part time lecturer in Shahrekord Payame Nour University and Shahrekord Applied Science University, Iran. Her research interests are livability and pedestrian activities in urban design and open spaces.

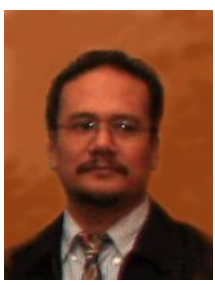

Mohamed Rashid Bin Embi was born in Malaysia $\mathrm{He}$ got his bachelor degree in architecture from University Technology Malaysia and he received his $\mathrm{PhD}$ of architecture, from University of Sheffield.

He is a deputy dean (development), Department of Architecture, Universiti Technology Malaysia. His expertise is computer aided design and design for future.

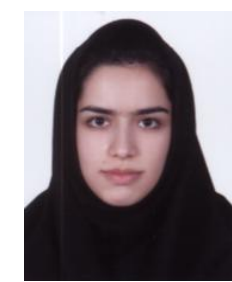

Parastoo Khademi was born in 1990, Shahrekord, Iran. She is studying civil engineering in University of Shahrekord, Iran. 